\title{
A process study of strategic entrepreneurship: viewing from ambidexterity and dynamic capability
}

\author{
Yang Dapeng ${ }^{1, a}$, Cui Jin $^{1, b}$ and Pan Songting ${ }^{2, c}$ \\ ${ }^{1}$ School of public affairs, Zhejiang University, Hangzhou, China \\ ${ }^{2}$ Party school of Zhejiang provincial committee the CPC, Hangzhou, China \\ ayangdp@zju.edu.cn bcuijin@zju.edu.cn cpansongting315@163.com
}

Keywords: strategic entrepreneurship, ambidexterity, dynamic capability

\begin{abstract}
As an emerging field of research, strategic entrepreneurship has gain lots of attention. However, the specific process of strategic entrepreneurship remains vague. This study try to unravel the process of strategic entrepreneurship through the view of ambidexterity and dynamic capability, a new framework of strategic entrepreneurship process combing the development of dynamic capability is raised.
\end{abstract}

\section{Introduction}

As the 21st century dawns, many companies across virtually all industries regard entrepreneurial actions as essential if they are to survive in a world increasingly driven by accelerating change(Lyon, Lumpkin, \& Dess, 2000). Many new firms were created, not only by the entrepreneur but also by established companies. Silicon Valley and many other high-tech zones have been benchmark for entrepreneurial companies. Entrepreneurial actions are a fundamental behavior of firms by which they move into new markets, seize new customers and/or combine (existing) resources in new ways. In the research field of entrepreneurship, it has not been long since a widely accepted definition was made (Shane \& Venkataraman, 2000), there are many research conducted in this field.

In the early stage, researches had mainly focused on the enterprising individuals, including the characteristics of entrepreneur and what did they do. Later researchers carried out discussion of entrepreneurship as a distinctive scholarly domain with its own research questions and theories, clarified the definition of entrepreneurship as a process rather than an event or embodiment of a type of person (Shane, 2012). Others include the environment of entrepreneurship, the process of corporate entrepreneurship and so on.

\section{Strategic entrepreneurship as an emergent research field}

Entrepreneurial actions are behaviors through which companies exploit opportunities others have not identified or exploited (R. D. Ireland, Hitt, Camp, \& Sexton, 2001). Ranft and O'Neill report that only about 25 percent of new ventures survive their first five years. Entrepreneurship focuses on growth and innovation related to risk and uncertainty, which may cause failure of newly established firms. To address this problem, researchers come up with a solution of integrating entrepreneurship with strategy management as they both are focused on how firms adapt to environmental change and exploit opportunities created by uncertainties and discontinuities in the creation of wealth (Hitt, Ireland, Camp, \& Sexton, 2001). The raise of strategic entrepreneurship is both needed in theory and practice.

Strategic entrepreneurship (SE) involves simultaneous opportunity-seeking and advantage-seeking behaviors and results in superior firm performance (D. R. Ireland, Hitt, \& Sirmon, 2003). In Ireland's later research, he clarified SE require firms' ability to keep a balance between exploration (opportunity-seeking) and exploitation (advantage-seeking). Since Ireland \&Hitt's milestone work, a lot of researchers have made investigation about the antecedent, process and dimensions of SE. 


\section{Process of Strategic entrepreneurship}

In research of SE process, there are two approaches: namely combination and integration. Combination means strategic activities and entrepreneurial activities are only put in one firm without reaction with each other, while integration requires reciprocity, in which strategic activities and entrepreneurial activities can prompt each other to help firms to get better performance.

In combination approach, SE is conducted by simultaneously pursuing advantage-seeking and opportunity-seeking activities (Hitt et al., 2001). Strategic activities and entrepreneurial activities are carried out linearly (D. R. Ireland et al., 2003). In the first stage, firms focus on managing resources strategically, as a foundation of applying creativity and developing innovation. Resource management can be seen as three steps: structuring the resource portfolio, bundling resources and leveraging capabilities. With knowledge accumulated in this stage, firms can implement sustaining or disruptive innovation and incremental or radical change can be achieved.

In contract, integration approach is much more complex and hard to complete. In this regard, balance of time and spatial problem should take into consideration (Kyrgidou \& Hughes, 2010). Firms have to iterate between episodes of opportunity identification, managing resources strategically, and opportunity exploitation through creating and deploying innovation. SE can be seen to balance resource distribution between exploration and exploitation (Duane Ireland \& Webb, 2007). Exploitation can enable existing knowledge through incremental innovation, and prompt performance to support exploration. Exploration occurs through integrating diversity internal and external firm knowledge, absorbing new knowledge and search for future success. However, exploration and exploitation differs in operational, structural and cultural mechanism, resulting integration approach difficult to conduct.

\section{Strategic entrepreneurship and dynamic capability}

The perhaps most direct precursor of strategic entrepreneurship may well be the "dynamic capabilities view" (Teece, Pisano, \& Shuen, 1997). This view argues that superior performance comes from a firm's capacity to change its resource base in the face of Schumpeterian competition and environmental change. Dynamic capabilities are defined as the firm's ability to integrate, build, and reconfigure internal and external competences to address rapidly changing environments(Teece et al., 1997). Importantly, dynamic capabilities reflect past learning processes, as they are a learned pattern of collective activity through which the organization systematically generates and modifies its operational routines in pursuit of improved performance.

This basic definition has been subsequently refined and extended (Eisenhardt \& Martin, 2000; Teece, 2007). What unites different approaches and definitions is the insistence on an organizational ability to alter its resource base. Thus, Helfat et al. (2007) synthesize prior conceptual work by defining a dynamic capability as "the capacity of an organization to purposefully create, extend, and modify its resource base”. Accordingly, dynamic capabilities may perform different tasks that alter the resource base, such as new product development, alliance formation, or post-acquisition integration (Eisenhardt \& Martin, 2000). According to the dynamic capability approach, a firm's capacity to alter its resource base indirectly influences economic profitability (Helfat and Peteraf, 2009). Superior dynamic capabilities enable firms to adapt more quickly and effectively to a changing business environment, creating a stream of temporary competitive advantages over time(Teece et al., 1997).

Recent work on dynamic capabilities has increasingly stressed the role of organizational processes for understanding how firms alter its resource base. (Teece, 2007) opens up the black box of dynamic capabilities by relating the concept to organizational processes of sensing and seizing business opportunities and the reconfiguring of resources. A firm's sensing ability critically depends on the organizational systems and individual capacities to learn and to identify, filter, evaluate, and shape opportunities. Once a business opportunity is identified, the organizational structure, procedures, and incentives influence whether and how a firm seizes the opportunity and creates a new strategic path. What is more, governance and organizational structures shape how 
firms reconfigure their specific resources over time. As we shall see, the dynamic capabilities view is quite akin to SE.

\section{Ambidexterity and dynamic capability}

\section{What is ambidexterity?}

Ambidexterity refers to an organization's ability to be aligned and efficient in its management of today's business demands while simultaneously being adaptive to changes in environment (Raisch \& Birkinshaw, 2008). It has emerged as a new research paradigm in organization theory, (Duncan, 1976) first used the term organizational ambidexterity, (March, 1991) put forward the core concept of exploration and exploitation explicating the key point of this field, Tushman \& O' Reilly III were the one who formally start the research of ambidextrous organization (Tushman \& O'Reilly, 1996). Raisch \& Birkinshaw(2008) made an overall review of organizational ambidexterity, explaining the antecedents, outcomes, and moderators of organizational ambidexterity. This is also one of the most cited papers in this field.

In Raisch \& Birkinshaw's review, they listed four main literature streams related to organizational ambidexterity. Here we summarized it as the table 1.

Table 1. Literature streams related to organizational ambidexterity

\begin{tabular}{|l|l|l|}
\hline \multicolumn{1}{|c|}{ Areas } & \multicolumn{1}{|c|}{ Focus } & \multicolumn{1}{c|}{ Implement mechanism } \\
\hline $\begin{array}{l}\text { Organizational } \\
\text { learning }\end{array}$ & $\begin{array}{l}\text { Exploration and exploitation } \\
\text { (March, 1991) }\end{array}$ & $\begin{array}{l}\text { Time separation, spatial separation (Lavie, Kang, } \\
\text { \& Rosenkopf, 2011) }\end{array}$ \\
\hline $\begin{array}{l}\text { Technological } \\
\text { innovation }\end{array}$ & $\begin{array}{l}\text { Incremental and radical } \\
\text { innovation (Tushman, 1986) }\end{array}$ & $\begin{array}{l}\text { TMT integration, organizational integration } \\
\text { (Jansen,, van den Bosch, \& Volberda, 2009) }\end{array}$ \\
\hline $\begin{array}{l}\text { Organization } \\
\text { design }\end{array}$ & $\begin{array}{l}\text { Efficiency and flexibility } \\
\text { (Duncan, 1976) }\end{array}$ & $\begin{array}{l}\text { Structural balance, contextual balance (Gibson \& } \\
\text { Birkinshaw, 2004) }\end{array}$ \\
\hline $\begin{array}{l}\text { Organizational } \\
\text { adaption }\end{array}$ & Continuity and change & $\begin{array}{l}\text { Long periods of convergence punctuated by short } \\
\text { periods of discontinuous change }\end{array}$ \\
\hline
\end{tabular}

As we have seen already, ambidexterity is widely used in many areas, yet several issues fundamental to this debate remain controversial. There remains many questions to be solved (Raisch, Birkinshaw, Probst, \& Tushman, 2009): Should organizations achieve ambidexterity through differentiation or through integration? Does ambidexterity occur at the individual or organizational level? Must organizations take a static or dynamic perspective on ambidexterity? Finally, can ambidexterity arise internally, or do firms have to externalize some processes? Here we try to figure out two basic parts: the nature of ambidexterity and how to measure it.

The first question is whether the two competing activities are continuous or orthogonally? Based on the assumption of continuity, the two activities can be seen as the two end of continuity, they will fight like a zero-sum game. As resources and routines needed are different as strategic actions differ, ambidexterity need to be implemented through time separation or spatial separation. However, if the two competing activities are dependent, then the two activities can be achieved at the same time.

As to the measurement of ambidexterity, category of the concept should be made first. Based on a summary of existing research, Raisch and Birkinshaw suggest there are three types of ambidexterity: structural ambidexterity, contextual ambidexterity, and leadership-based ambidexterity(Raisch \& Birkinshaw, 2008). Ambidexterity in organizational structures is achieved by "developing structural mechanisms to cope with the competing demands faced by the organization for alignment and adaptability" (Gibson \& Birkinshaw, 2004). Contextual ambidexterity is defined as "the behavioral capacity to simultaneously demonstrate alignment and adaptability across an entire business unit” (Gibson \& Birkinshaw, 2004). Tushman and O’Reilly (1997)(Tushman \& O’Reilly, 1997) state that ambidexterity is facilitated by the top-management team's internal processes, such as information, decision, and conflict management. Several studies described leadership processes as a supporting factor when implementing structural or contextual ambidexterity(Smith \& Tushman, 2005).

Cao et al. (Cao, Gedajlovic, \& Zhang, 2009a) identified two dimension of ambidexterity: balanced ambidexterity and combined ambidexterity. Simsek (Simsek, Heavey, Veiga, \& Souder, 
2009) divided ambidexterity into four type according time dimension and structure dimension, namely harmonic balance, cyclical balance, partitional balance, and reciprocal balance.

For different category, the measurement of ambidexterity can be different. Early literature use one dimension to measure(Rothaermel \& Alexandre, 2009). The most literatures used the product of two competing activities to measure ambidexterity(Gibson \& Birkinshaw, 2004). He and Wong(He \& Wong, 2008) distinguished the two dimension of ambidexterity and use the product of them to measure combined ambidexterity while the absolute value of their difference is to measure balanced ambidexterity. Since He and Wong's work, a consensus was formed.

\section{Ambidexterity as a dynamic capability}

The ability of senior managers to seize opportunities through the orchestration and integration of both new and existing assets to overcome inertia and path dependencies is at the core of dynamic capabilities (O’Reilly \& Tushman, 2008), it requires organization to be ambidextrous to gain effective dynamic capability. For organizations to be ambidextrous, i.e. compete simultaneously in both mature and emerging markets, this inevitably requires senior leaders to manage completely different and inconsistent organizational alignments(Tushman \& O’Reilly, 1997). The key success factors needed to succeed at exploitation demand a short-term time perspective, efficiency, discipline, incremental improvement and continuous innovation. The alignment of competencies, systems, structure and culture to execute this strategy is completely different from the alignment needed for exploration, where the key success factors emphasize a longer time perspective, more autonomy, flexibility and risk taking and less formal systems and control.

Dynamic capabilities, those processes that permit an enterprise to build, integrate, and reconfigure organizational assets, offer one way out of the inertial dynamics associated with success. Unfortunately, the management challenges of ambidexterity, in which organizations simultaneously explore and exploit and compete with different business models, are substantial. We review the existing literature on exploration, exploitation and ambidexterity to illustrate how the origins and consequences of dynamic capabilities affect an organization's ability to adapt. We then provide several examples of dynamic capabilities and ambidexterity in action.

\section{Ambidexterity in strategic entrepreneurship}

As we have noted, the integration approach of SE lies largely on keeping a balance resource distribution between exploration and exploitation, what is exactly seen as organizational ambidexterity. Organizational ambidexterity, defined as an organization's ability to be aligned and efficient in its management of today's business demands while simultaneously being adaptive to changes in the environment, has gained increasing interest in recent years (Raisch \& Birkinshaw, 2008). The advantage-seeking activities (i.e. exploitative activities) of SE are related to firm's ability to keep today's performance, which involves managing strategically, effectiveness and short-term benefit is emphasized. While the opportunity-seeking activities (i.e. explorative activities) of SE resemble firm's ability to adapt the dynamic environment to pursue future performance, which involves applying innovation and creativity, efficiency and long-term benefit matters a lot.

By now, literature discussed the antecedents and the process, there wasn't a consensus on the factors triggering SE, and former researcher haven't unravel the interdependence of exploitation and exploration. Based on these literatures, here we put forward a new strategic entrepreneurship model to explicit the underlying process of this phenomenon, and explain how ambidexterity works in achieving better performance and reduce the risk simultaneously. 


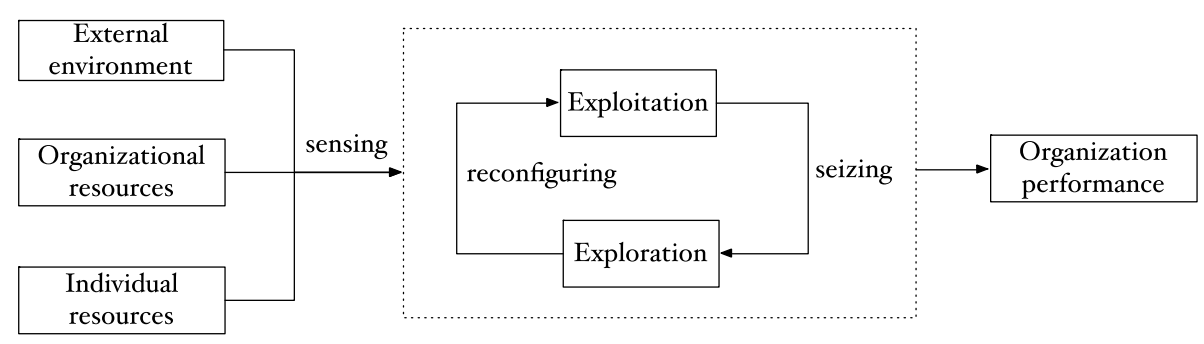

Figure 1. A process model of strategic entrepreneurship

This model moderated the "input-process-outcome" model, synergizing the antecedents of SE, using ambidexterity to explain the process of strategic and entrepreneurial balance, applying dynamic capability to explicit the mechanism of the phenomenon, try to make a better understanding of strategic entrepreneurship and offer references for practitioners.

Antecedents of SE include external environment, organizational resources, and individual resources. External environment involves the rapid changing political, economic, and cultural environment. At organizational level, organizational culture and structure play important role in initiating SE. Individual resources refer to strategic vision, entrepreneurship mindset and social capital of leaders and top management team.

As to the process of SE, we prefer a combined approach to effective SE. Literatures have found that explorative activities support organizational refinement and expansion, while exploitative activities offer knowledge base for further exploration(Cao et al., 2009a; He \& Wong, 2008). Thus the key of SE lies in the combination and mutual benefit of explorative activities and exploitative activities.

Dynamic capability works throughout the process. The sensing ability based on the individual resources, involves searching opportunities from external environment, identifying whether the structure and culture fits the ambidextrous behaviors. The seizing ability refers to organization's ability to implement the external opportunity and apply it together with operating activities, which may help with the effectiveness of exploitative activities. And reconfiguring ability refers to realigning resources especially knowledge into pursue of new opportunities. By combination and mutual benefiting of the two competing activities, firms can adapt to environmental change better and create wealth.

\section{Acknowledgement}

This research was financially supported by the National Natural Science Foundation of China (Grant NO. 71473229) and Zhejiang Provincial Natural Science Foundation of China(Grant NO. LQ14G030024).

\section{References}

[1] Birkinshaw, J. (2004). Building ambidexterity into an organization. Sloan Management Review, 45, 47-55.

[2] Cao, Q., Gedajlovic, E., \& Zhang, H. (2009a). Unpacking Organizational Ambidexterity: Dimensions, Contingencies, and Synergistic Effects. Organization Science, 20(4), 781-796.

[3] Duane Ireland, R., \& Webb, J. W. (2007). Strategic entrepreneurship: Creating competitive advantage through streams of innovation. Business Horizons, 50(1), 49-59.

[4] Duncan, R. B. (1976). The ambidextrous organization: Designing dual structures for innovation. The Management of Organization, 1, 167-188.

[5] Eisenhardt, K. M., \& Martin, J. A. (2000). Dynamic capabilities: what are they? Strategic Management Journal, 21, 1105-1121.

[6] Harreld, J. B., O'Reilly, C. A., \& Tushman, M. L. (2007). Dynamic Capabilities at IBM: Driving Strategy into Action. California Management Review, 49(4), 21-43. 
[7] He, Z.-L., \& Wong, P.-K. (2008). Exploration vs. Exploitation: An Empirical Test of the Ambidexterity Hypothesis. Organization Science, 15(4), 1-15.

[8] Ireland, D. R., Hitt, M. A., \& Sirmon, D. G. (2003). A Model of Strategic Entrepreneurship: The Construct and its Dimensions. Journal of Management, 29(6), 963-989.

[9] Kyrgidou, L. P., \& Hughes, M. (2010). Strategic entrepreneurship: origins, core elements and research directions. European Business Review, 22(1), 43-63.

[10]Raisch, S., \& Birkinshaw, J. (2008). Organizational Ambidexterity: Antecedents, Outcomes, and Moderators. Journal of Management, 34(3), 375-409.

[11]Raisch, S., Birkinshaw, J., Probst, G., \& Tushman, M. L. (2009). Organizational Ambidexterity: Balancing Exploitation and Exploration for Sustained Performance. Organization Science, 20(4), 685-695.

[12] Shane, S., \& Venkataraman, S. (2000). The Promise of Entrepreneurship As a Field of Research. Academy of Management Review, 25(1), 217-226.

[13]Teece, D. J. (2007). Explicating dynamic capabilities: the nature and microfoundations of (sustainable) enterprise performance. Strategic Management Journal, 28, 1319-1350. doi:10.1002/smj.640

[14]Tushman, M. L., \& O’Reilly, C. A., III. (1997). Winning through innovation: A practical guide to leading organizational change and renewal. Harvard Business Press. 